\title{
Hostile urban architecture: A critical discussion of the seemingly offensive art of keeping people away
}

\author{
Karl de Fine Licht \\ Chalmers University of Technology, Research Institute of Sweden (RISE) and the \\ University of Gothenburg and Center for Research Ethics and Bioethics (CRB) at \\ Uppsala University, Karl.licht@ri.se
}

DOI: http://dx.doi.org/10.5324/eip.v11i2.2052

(cc)BY
Attribution 4.0 International License, which permits unrestricted use, distribution, and
reproduction in any medium, provided the original author and source are credited.

For many years, some urban architecture has aimed to exclude unwanted groups of people from some locations. This type of architecture is called "defensive" or "hostile" architecture and includes benches that cannot be slept on, spikes in the ground that cannot be stood on, and pieces of metal that hinder one's ability to skateboard. These defensive measures have sparked public outrage, with many thinking such measures lead to suffering, are disrespectful, and violate people's rights. In this paper, it is argued that these views are difficult to defend and that much more empirical research on the topic is needed.

Keywords: Defensive architecture, hostile architecture, anti-homeless spike, bumproof benches, urban planning, well-being, right to public space

For many years, urban architecture has aimed to exclude unwanted groups of people from different places, a prime example of which is the "gated community." There, a wall and a team of security guards keep out unwanted individuals, typically anyone who has not been invited by residents.

The existence and effects of these communities have been widely discussed in the literature (e.g., Blakely and Snyder 1997). For example, do these communities make people less happy and more insecure than individuals living outside the community's walls? Is it fair for a community to seal itself off in this way, thereby not taking part in the challenges that everyone else faces? Do crime rates actually decrease in these neighborhoods?

In recent years, the desire to exclude "unwanted" behaviors and people has moved into the public sphere, leading to the establishment of what is called "defensive planning," "defensive urban architecture," "excluding architecture", "disciplinary architecture", "hostile architecture," and even "evil architecture." Examples include benches whose design prevent people from lying down on them and spikes in the ground that dissuade panhandling. The use of defensive architecture in public spaces has caused uproar, with some people arguing that it is not a dignified way to treat the worst-off in the population. ${ }^{2}$ 
Although this sort of defensive architecture is widely used in many countries, such as Sweden, the UK, and the United States (Edin 2014), it has not undergone a systematic ethical analysis. ${ }^{3}$ The present paper is the first to attempt such an analysis. ${ }^{4}$ According to a recent review in the Journal of Urbanism titled "A Starting Point for Practical and Methodological Discussion," Giovanni de Grandis (2013) argued that much more discussion is needed about urban planning from an applied ethics point of view. Thus, the present article attempts to fill this gap. It will hopefully inform the discussion and pave the way for the arguments in it to be more transparent and more clearly stated. ${ }^{5}$

In this paper, I will evaluate different arguments against the use of hostile architecture, mostly in the public debate, and when necessary, I shall aim to give greater credence to them by noting the normative theories to which they are related. I choose to focus on these arguments because most news articles and opinion pieces written by scientists and activists are negative. I will analyze and question the notion that decision-makers have fully considered the ramifications of defensive architecture. "Decision-makers" here refers to people who have the power to make decisions about defensive architecture, including politicians, landlords, and owners of small shops.

Although there are many relevant moral questions about defensive architecture, such as whether politicians should condemn these defensive measures even in cases when they should allow them to exist, I will not discuss these questions here. It is also important to note that different groups of policymakers might have conflicting reasons when assessing whether to implement a new defensive feature in one and the same place. Politicians might have one set of responsibilities, while individual shop owners might have another. This means that we cannot know exactly what to do until we have considered all these groups and tried to ascertain what their responsibilities are. This is not the aim of this paper, as it is a massive undertaking. I shall use some specific central cases regarding defensive architecture that probably also have a bearing on the other areas of decision-making.

Furthermore, the subject of this paper, defensive architecture, is distinct from a "hostile cultural environment," or laws preventing people from performing certain actions, such as sleeping in public spaces. Urban sociologists, legal scholars, and others have written extensively about the "soft policies of exclusion" or how the culture in a particular part of town can be so hostile toward certain groups of people that they find it difficult to live there (e.g., Mitchell 2003; Thörn 2011). Although this is an interesting line of discussion, and although defensive architecture might help to create such an environment, the permissibility of creating such a culture or enacting those kinds of laws is not at issue here. My focus is limited to the actual designs, not the culture that surrounds and is partly responsible for them.

This paper will first discuss some different and important defensive measures in urban planning and then determine whether the designs discriminate against the less fortunate, whether they violate people's dignity, and whether they violate people's rights. Ultimately, I will argue that defensive architecture is at least acceptable in certain contexts and to achieve certain goals, but that we need to conduct further empirical research in order to speak knowledgeably about the topic. Given that defensive architecture is so widely criticized and condemned, this result is indeed interesting. ${ }^{6}$ 


\section{Examples of defensive urban architecture}

There are many examples of defensive urban architecture in both public and private spaces (Lockton 2011). Such architecture can be constructed in a number of ways. First, existing infrastructure can be modified so that it becomes impossible to use it in the same way as before. For example, "anti-hobo benches," "bum-proof benches," and "Camden benches" are designed so that they are impossible, or at least very uncomfortable, to sleep on. ${ }^{7}$ The seats on the bench might be wavy or separated by armrests, or the bench might slope. Sloping seats can be combined with slippery materials, such as stainless steel, to make them even harder to sleep on. In addition, backrests are usually either cut off or very low. Any combination of these modifications can make it extremely difficult to get substantial rest on benches.

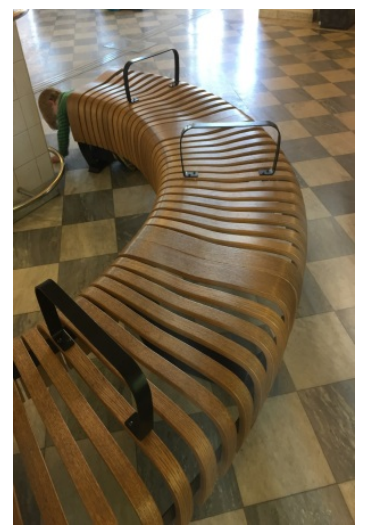

This is an example of an "unsleepable" bench from Varberg train station (Sweden).

Second, elements can be added to a space to deter some of its possible uses. For example, "anti-homeless spikes" can be placed in the ground or on windowsills, preventing people from standing or sitting there. A similar but less conspicuous measure is to place a large plant or other object in places where panhandlers commonly congregate. In the same vein, "pig ears" or "skate stoppers" can be used to prevent people from skateboarding (Howell 2001). These are metal pieces bolted onto different surfaces" aimed at preventing skateboarders from jumping ("ollying") onto benches and curbs. ${ }^{10}$

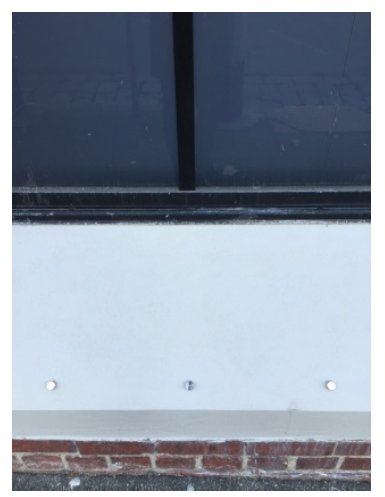

The metal pins on the bottom are skate stoppers. They are meant to stop skateboarders from grinding (Melbourne, Australia).

Third, objects may be removed from public spaces so that certain functions disappear. For example, removing benches from a mall where people sit and drink beer can be an effective design measure. This is not discussed nearly as much as the first two modes of design, but it leads to a similar - and sometimes far more effective - outcome. In many cases, it is much easier to remove a feature than to alter it or construct new architecture. 
All the measures discussed thus far have been decidedly forceful in the sense that one can clearly no longer use the infrastructure in the same manner as before; it is physically impossible to stand on spikes or to sit in midair where a bench used to be. However, not all defensive measures are this forceful (e.g., Andersson 2014), which suggests that defensiveness or hostility can vary in its intensity.

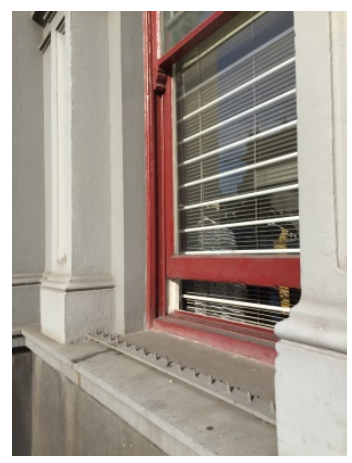

This is a window in with anti-homeless spikes (Melbourne, Australia).

Mildly defensive measures act more like nudges (e.g., Thaler and Sunstein 2008) and will probably be used more widely than more conspicuous defen sive architecture in the future, because most liberal, middle-class individuals react negatively to spikes and similar designs. Two common defensive "designs" use color and sound to avoid unwanted behavior. Off-putting colors, "anti-teen music" (such as classical music), and high-frequency sounds only young people can hear are employed to encourage people to congregate elsewhere.

In this paper, I will focus on the more forceful measures, such as spikes and Camden benches. If we can show that some of the common arguments against these measures fail, we will have even stronger reason to believe that using "mildly defensive architecture" is not wrong, which will allow the debate to move forward.

There are also other forms of what is sometimes called defensive architecture, whereby public areas are simply closed off or where large areas are made practically inaccessible to others than a select group (e.g., Flusty 1994). These measures will not be addressed in this paper as they, in my view, have their affinity with gated communities rather than the design measures mentioned here. The common feature with the defensive measures described here is that they do not make a large area inaccessible; they simply make it difficult to conduct a particular activity in a small area.

\section{Consequences}

Many objections to hostile architecture have been raised in the public debate, most of which are consequentialist in nature. For example, it is argued that defensive architecture is

an outdated, exclusionary fort architecture... all of these are small things that, for most of us, pass unnoticed. But for those who are so vulnerable as to not have a bed to sleep in, they are another slap in the face-very clear signals that they are not welcome in the social community. (Andersson 2014, 58, translation mine)

Other authors make similar arguments: 
The psychological effect is devastating [for those the architecture is designed against]... Ironically, it doesn't even achieve its basic goal of making us feel safer. There is no way of locking others out that doesn't also lock us in. The narrower the arrow-slit, the larger outside dangers appear. Making our urban environment hostile breeds hardness and isolation. It makes life a little uglier for all of us. (Andreou 2015).

The renowned and hugely influential scholar Jane Jacobs and the school of "new urbanism" have also been interpreted as opposing defensive architecture on the grounds that it makes the city landscape less diverse and thereby worse for most people (Ederyd and Aneljung 2015, 26). The idea here is that you take away certain qualities from the urban landscape, which in turn have adverse effects on the things we value. There are many other relevant arguments regarding defensive architecture, such as those concerning respect and rights. This means that even if we find that the best possible outcome in terms of consequences is to utilize defensive architecture, we might have decisive reasons against implementing it (more on this in the sections below).

More specifically, the strongest possible consequentialist argument against utilizing defensive architecture would be that it has a negative impact on most people's well-being, that it is particularly bad for the worst-off, and that overall it has no positive effects for most, or any, people. ${ }^{11}$ In cases when defensive architecture has positive effects, the magnitude of these effects is much smaller than that of the negative effects, thus practically negating the positive effects.

Assuming that these empirical assumptions are true, the prohibition against the use of defensive architecture could be defended on many disparate normative grounds such as classic utilitarianism (e.g., Sidgwick 1907; Tännsjö 1998), prioritarianism (e.g., Parfit 1991, 2013), egalitarianism (e.g., Temkin 1993), or sufficientarianism (e.g., Anderson 1999), all of which support the argument. There will be local exceptions, of course, where particular types of architecture in particular places will, on the whole, yield positive consequences and will hence be permissible or even strongly advisable to erect. However, if the argument against defensive architecture holds in general, we should, as a rule of thumb, not utilize defensive architecture. ${ }^{12}$

There are a number of problems, however, with the empirical premises of the argument against defensive architecture, the most serious of which is that few empirical studies support the negative claims regarding the effects of defensive architecture (e.g., Edin 2014) ${ }^{13}$ More precisely, what we need to know is whether defensive architecture works in the sense that it is supposed to - such as to keep certain behaviors and groups away from an area - and what the direct and indirect effects are on people's well-being. For example, do defensive measures have the devastating psychological effects suggested in the quote above, or are they nonexistent due to the fact that those who are targeted hardly notice them? These and other questions need to be answered before we can say more with any certainty. ${ }^{14}$

However, even if it is true that substantially more empirical studies are needed, we can still make a case for the implausibility of the negative thesis that the utilization of defensive architecture, in general, is morally wrong. First, assuming a negative impact on well-being, not all groups whose behavior is targeted by defensive 
measures are among the worst-off. Skateboarders, who are predominantly white middle-class males (Karsten and Pel 2000; Donnelly 2008) are just one example of this.

Second, in cases where the negatively affected group is among the worst-off, a wide range of situations may exist whereby another group in the same - or similar circumstances benefits. If we do not want to give absolute priority to the worst-off, we have to weigh the negative impact on one group against the positive impact on the other. ${ }^{15}$ In conducting this assessment, we need to, according to many of the standard normative theories mentioned above, take into account the extent to which defensive architecture negatively or positively affects individuals in different groups, and how many individuals belong to these groups that are affected. ${ }^{16}$ Put another way, it is easy to see that in many instances there may be good reason to favor the utilization of defensive architecture, or the case against its use may not be clear cut.

For example, there could be consequentialist reasons for the use of defensive architecture at bus stops. In many countries, people who use public transportation are among the worst off (e.g., Titheridge et al. 2014, 8). Many of them feel unsafe at bus stops when other people are sleeping on benches and where panhandling occurs. More criminal activity has been documented in hot spots for panhandlers (e.g., Loukaitou-Sideris 1999). Quite plausibly, many more individuals use the bus stops solely for the purpose of taking the bus than use it to sleep or to sell their goods. If defensive architecture can help to prevent panhandling and people sleeping on benches, then the largest of the less fortunate groups would be better off, providing a consequentialist reason in favor of utilizing defensive measures, all else being equal. Of course, this would be at the expense of other groups that are poorly off (in this case, homeless people and panhandlers), but it is not at all clear that this group will be that badly affected by the architecture. Even if this were so, we need to weigh the effects on each of the groups, which means that we have a decidedly more complicated argument on our hands, not knowing what exactly this is going to yield.

Third, assuming that we give greater priority, but not absolute priority, to the worst-off, it seems evident that we will have cases in which the potential impact on the better-off will trump the negative effects on the worst-off. When the worse-off population is not the largest group, some situations will result in which the negative effects on the worse-off group will be outweighed by the larger better-off group. ${ }^{17}$ For example, being in green areas enhances people's ability to relax and be healthy and leads to a higher quality of life (Mitchell and Popham 2008; Stigsdotter et al. 2010). However, when parks become overrun by homeless people and drug addicts, they become less available to others (Kelling and Coles 1996; Elickson 1996). A consequentialist argument can be said to exist in favor of defensive architecture, if it allows us to achieve benefits for the majority (who we might assume are better off) by pushing some people who are less well-off out of parks, and if those who are pushed out do not experience any significant negative effects.

Fourth, and last, defensive architecture may actually benefit those against whom it is designed. For example, public health researchers have noted that people who ride their skateboards in skate parks are much less likely to get injured than those who ride on city sidewalks (Forsman and Ericsson 2001; Lustenberger et al. 2010). If a city has skate parks, and if skate stoppers direct skateboarders to these parks, defensive architecture would yield positive consequences. In addition, if benches 
that cannot be slept on are installed at bus stops, they could lead people to seek more secure places to sleep, such as shelters, which benefit everyone. Again, empirical studies are needed to ascertain whether these positive effects can be achieved. However, they do not seem to be less likely to happen than their negative counterparts, at least if defensive measures are combined with information and dialog.

In this section, I have tried to show that the arguments against the use of defensive architecture might fail, at least to some extent. However, two measures must be taken before we can be at all certain that these conclusions are valid.

First, we need more studies on the effects of defensive designs on people's behavior. These studies should ask questions such as: Are people who are not allowed sleep on benches more inclined to break into people's homes to find shelter? Do skateboarders go somewhere else to skate after skate stoppers are installed, or do they develop tricks to avoid them? Of course, these kinds of studies might be difficult to do for various reasons, but without them it is presumptuous to assert that defensive architecture has a specific range of negative effects.

Second, we need to examine the effects of these designs on people's short- and long-term well-being, including the populations at which the designs are aimed and those the designs are meant to protect. ${ }^{18}$ Of course, said the arguments made in this section should not be interpreted as giving decision-makers decisive reason to erect defensive measures anywhere they please. This form of architecture may indeed be problematic in its design or in many locations. Nevertheless, a more nuanced view can help to assess which designs these are and when and where they are inappropriate, given a set of defined aims and goals.

\section{Respect}

Another common objection against hostile architecture is that we have a duty to treat people with respect. Proponents of this view maintain that this duty cannot be fulfilled when we use hostile measures as means to exclude. For example, many people say that people are treated "like animals" (e.g. Lindberg 2015). It is not difficult to understand that trying to keep people away with defensive measures is an act of disrespect. However, the question is how the notion of "respect" should be spelled out and whether a reasonable definition of respect really implies that we necessarily treat targeted in dividuals with disrespect. ${ }^{19}$

There are many ways to interpret respect. One common idea in moral philosophy and elsewhere is the Kantian perspective, which states that we should not perceive people as instruments or objects (the "mere means principle"), but as people who can be reasoned with (Kant 1785; Wood 1999; Darwall 2006). If skate stoppers are installed without initiating a discussion with skateboarders, then we are in a sense treating them as objects not worthy of an opinion on the situation. Thus, defensive architecture should be implemented only after engaging in a two-way conversation with those affected.

Of course, this is not to say that we are not allowed to make use of defensive architecture. For example, if the majority believes that defensive measures should be used after considering opponents' perspectives, the utilization of defensive architecture appears to be in line with treating people with respect. Since the majority in some situations has quite good arguments in their favor, as in the bus 
stop example above, it may be possible to apply defensive measures with respect in a range of cases.

Even though the mere means principle is not decisive with regard to our case, many Kantian duties might be relevant here. The most pressing question regarding this form of design is aimed at keeping the homeless away from the public sphere. This is because they are in real need of help. Kant explicitly says that:

...it is our duty: not to avoid places where we shall find the poor who lack the most basic essentials, but rather to seek them out; not to shun the sick-rooms or debtor's prisons in order to avoid the painful sympathetic feelings that we cannot guard against. (DV 126)

This is relevant to our case since it can be argued that we are trying to do something similar with defensive architecture. We are trying to exclude those who are creating sympathetic feelings in us. However, I am not at all certain that this is what we actually want to do. First, in some cases, it is quite obvious that those who buy benches, for instance, just buy the cheapest ones, or those with the most elegant design, or base their choice on some other reason that has nothing to do with trying to avoid homeless people. In these cases, as long as the unawareness is non-culpable, it seems that no wrong has been done. Of course, if the duty is "not to avoid" instead of "not trying to avoid" seeing the poor, the latter duty is still not fulfilled in the case of non-culpable ignorance. However, using a criterion of rightness that is not dependent on the agent's intention in this way is surely quite far off from the Kantian tradition.

Second, although we have a duty not to shun the poor, the noisy, or other disagreeable group, we do not have a duty to allow them to be everywhere. For example, I probably do not have a duty to let one or a few homeless people into my house and let them live there -especially if they have a record of mental illness or are the victims of substance abuse. This is because I (or at least many of the people I am implicitly referring to here) would be too worried to get on with my own life. Of course, we have to sacrifice some things in favor of helping people, but going to these lengths should probably be seen as supererogatory and not something we are obligated to do.

One could also logically apply this line of reasoning to some of the important defensive architectural designs. For example, placing a flowerpot or similar obstacle outside your store or home so that beggars cannot sleep in your doorway and scare away your customers, or make it difficult for you to exit, is probably in itself not that problematic from a Kantian point of view. Furthermore, if you set up benches outside your house or on your courtyard to feel a bit safer, that is not, as I understand it, something that should be seen as disrespectful. We should be able to prioritize how we help people in need. Making it impossible to stand outside stores or in stairwells, or sleeping on benches should not be that detrimental to their chances of fulfilling their needs. Of course, we are not helping them either, but this is not something that is always obligatory.

Third, at least in Western welfare states, where shelters are often available for people to sleep at night, one might believe that we should try to nudge people not to sleep outside. This is because it is dangerous in different respects: individuals could be robbed, sexually assaulted, or suffer from poor health when they sleep outside. Of course, this could also happen at shelters, but the risk is less pronounced. ${ }^{20}$ 
Moreover, the fact that we know that panhandlers have many places to sell their wares and beg for money makes the duty of beneficence even less pressing. This means that we will not avoid them, which was Kant's concern in the quote above. Rather, we will not meet up with them everywhere in every possible form (such as lying asleep on benches).

Another way in which defensive architecture can be interpreted as disrespectful that will be discussed here, is when demeaning views are leveled against those at which the architecture is aimed. ${ }^{21}$ Compare this notion with the discussion about choosing not to have children with disabilities (McMahan 2005, 83-88). Through many different screening programs, doctors can usually determine whether a child will be born with a disability or disease. This information can then be used to choose a "normally functioning child" instead of a child with disabilities. However, some believe that such screenings should not be performed because they imply that people with disabilities are less worthy than those without disabilities. Proponents of this idea view such practices as disrespectful, regardless of whether individuals with disabilities know about the screenings or how they interpret the situation, because the action of screening for disabilities expresses the view that "the rest of us are trying to prevent the existence of the rest of you."

Defensive designs do not, however, necessarily express contempt toward the less fortunate. First of all, some defensive measures aim to prevent specific behaviors in specific locations, not discriminate against entire groups. This is similar to a common saying among defense lawyers: "Defend the individual, not the criminal act." Of course, certain actions are strongly correlated with certain groups. For example, people living in poverty who have nowhere to sleep are more likely than others to sleep outdoors. However, if we believe that people sleeping in a certain spot are problematic, regardless of whether they are homeless, then we are concerned with the behavior, not a group. Evidence for this being true some of the time are urban planners who have built defensive architecture and explicitly stated that they are trying to include all groups in public spaces (e.g., Ederyd and Aneljung 2015, 22).

Second, even when decision-makers try to exclude certain groups, designs do not necessarily and inherently disrespect these groups. For example, skate stoppers may be installed because skateboarders do not respect that people living in that area need to sleep, as opposed to the argument that people do not want to see or consider the viewpoints of skateboarders or because they believe that skateboarders have less moral worth. Or a business owner may reluctantly place a large flower pot outside her small neighborhood store; although she may think that people should be able to stand there, her customers may not share this belief and will thus not step inside her store when panhandlers are outside. Since the owner cannot afford to lose business, she is forced to take certain defensive measures. Thus, defensive architecture is not necessarily malicious; it may be intended to ensure that all groups are treated with respect.

\section{Rights}

The last common objection to defensive architecture is that everyone has a right to public space; that defensive measures are a violation of that right and are thus morally wrong.

For example, Anderson (2014) writes that defensive measures mean that only certain groups are welcome in an area, although everyone has an equal right to be 
there. Montero Bravo, an assistant professor at Konstfack University College of Arts, Crafts, and Design, is another proponent of this claim. He states that everyone has a right to public space but that defensive architecture excludes some groups and is thus illegitimate. ${ }^{22}$ However, people's "right" to public space is not precisely defined. For example, in his seminal work, The Right to the City, Mitchell (2003) does not go into sufficient detail to say whether the right to public space is violated in the context of defensive architecture.

Ideally, a rights-based argument against defensive architecture would clarify that individuals have an absolute right to use public space, which would be violated by defensive architecture. This right should be defined in a relatively clear and precise manner and should not have counterintuitive implications. ${ }^{23}$ Such an argument would give homeless people, skateboarders, or other affected groups the right to sleep or skate (almost) wherever they want in public spaces and would oblige decisionmakers to fulfill that right. However, it is not easy to see how such an absolute right to public space could be understood for it to be reasonable. I will be discussing some possible in terpretations below and will seek to demonstrate why they fail.

Libertarianism, a widely held view concerning absolute rights, may be relevant to our topic (Narveson 2011). According to this view, individuals have an absolute and natural right to their body and property (if it is obtained in a just way). As long as people do not violate the (natural and absolute) rights of others, they are allowed to make their own choices, irrespective of the consequences (e.g., Nozick 1974; Narveson 1988). For example, if I want to ruin my life by taking drugs, that is my decision, and no one is allowed to force me to stop. Libertarians readily admit that people should strive for certain values and avoid others, which means that people can make the "wrong" choices and cause unfavorable outcomes for themselves and others. However, this does not mean that others are justified in forcing people to make better choices; those people simply should have made better choices, given the opportunities they had.

There are at least two problems with arguing against defensive architecture on libertarian grounds. First, much of the controversy about defensive architecture is focused on private property. Since we are allowed to do as we please with our private property, and if we assume that most property was obtained in a just way, then defensive architecture does not violate rights. ${ }^{24}$ In fact, preventing someone from installing defensive architecture would violate his or her rights. Public space could be defined to include private property, but the argument that everyone has an equal right to all public spaces would become controversial, to say the least.

Determining what is acceptable in public spaces is more difficult and could thus render an argument against the use of defensive architecture. It could be argued that people cannot be excluded from spaces without their consent and without being compensated. There are, however, several problems with this suggestion. First, many of the seemingly public spaces in which defensive architecture is employed may actually be private, at least in a moral sense. For example, if a storeowner legitimately owns the piece of property where she sells her goods, then it might actually be the case that she has the right to the strip just outside her store. Thus, the claim that defensive measures violate people's rights is further invalidated.

Second, according to libertarianism, defensive designs are often not a violation of anyone's rights because we do not violate people's natural, absolute rights by not helping everyone equally. ${ }^{25}$ As long as no one's property is destroyed and there is 
en ough public space to go around, as the Lockean proviso states, then creating places for people to sit should be considered ben eficial and hence not a violation of rights. ${ }^{26}$

According to libertarian theory, there is no reason to believe that defensive architecture violates people's absolute rights. Interpreting the content of absolute rights in another way would either yield a right that is counterintuitive or would not give us a strong argument against using defensive architecture. We can use a number of ideas about rights in the debate to corroborate this.

First, many people believe that everyone has a right to public space in the sense that they are allowed to be there on equal terms (e.g., Mitchell 2003). Even if we interpret this idea in absolute terms, defensive designs do not violate this right. Defensive designs make certain behaviors impossible in very small areas, but this is the same for everybody, and people can still sleep and skate in public spaces, even if they are prohibited from doing it on that particular spot. Admittedly, defensive designs do make it somewhat more uncomfortable to live in public spaces, as people then need to sleep on the ground or ask for money in less populated places. However, in general it is possible to use public spaces in the way you like. ${ }^{27}$

Second, some people believe that individuals" "right to public space" affords them an equal, or almost equal, right to control that space (e.g., Lefebvre 1968; Harvey 2008). They may think, for instance, that the views of those who are affected by a decision should be considered. Even if true, this right is interpreted in an absolute way, and even if we assume that this right is not fulfilled today - that we hold asymmetrical power over the homeless, skateboarders, and disfranchised groups in general - we cannot be certain that shifting this power balance would have the desired effect. In addition to people who currently control the public space, less fortunate groups could potentially also support defensive architecture to end the behavior of public sleeping. Thus, we cannot know what the result of a power transfer would be and so should be cautious in our discussions on that topic.

Third, it could be argued that we have an equal and absolute right to feel welcome in public spaces. The idea that we have such an absolute right might come from the discussion on the notion of "ambient power": "[A]mbient power works ... through the experience of space itself, through its ambient qualities... Accessible yet closed, inclusive yet controlled, the very openness of this commercialized public space is precisely what allows consumers to be constructed through a logic of seduction" (Allen 2006, 442). However, it seems absurd to say that the experiences of a small fraction of the population, such as skateboarders, should have absolute weight, in the sense that it is not, under certain circumstances, permissible to make them feel unwelcome. ${ }^{28}$ Furthermore, it seems plausible that the negative aspects of different types of ambient power could be cashed out in terms of negative effects on welfare or a lack of respect toward the less fortunate. If this is true, then we have to examine whether defensive architecture leads to negative effects or whether it is disrespectful, which is not obvious, as we have seen above.

Fourth, it seems self-evident that we do not have an absolute right to do whatever we want in public spaces. For example, playing loud music at night and threatening people are not acceptable. Instead, we might have a prima facie right to do some things in public spaces. For example, we have the right to protest against social injustices and to wander, enjoying the environment. However, these rights must be weighed against other people's prima facie rights, such as the right for people to have some control over the areas in which they live and to feel safe. For example, if the majority of the population in an area wants to prohibit skateboarding at night 
because it destroys property and causes disturbances, and skateboarders are not willing to adjust their behavior, even after several meetings with the people living in the neighborhood, then defen sive measures may be necessary.

All of this suggests that if we have some right to public space, it is not absolute; it is prima facie and must be weighed against other people's rights. Of course, just because we do not have an absolute right to public space does not mean that every limitation of a public space is just; for instance, some limitations could be unfair if they are not reasonably sensitive to everyone's needs. However, being sensitive to everyone's needs does not necessarily mean that defensive designs should not be implemented; rather, the consequences must be considered, and the designs must be implemented with respect. In sum, one's "right to public space" will have to be cashed out in terms of the consequences of defensive architecture and respect.

\section{Conclusion}

In this paper, I sought to demonstrate that some of the arguments against defensive architecture are not always and necessarily viable. Cases may exist in which defensive architecture negatively affects the well-being of the worst-off, where it is a clear sign of disrespect, and where people's rights, on the whole, are violated. However, I have tried to show that we might, on the whole, have beneficial effects from defensive architecture; that people are not necessarily treated with disrespect by this architecture, and that it is not at all clear that the (prima facie) right to public space in turn yields a prohibition against defensive architecture.

That being said, we need to conduct much more empirical research on the impact of defensive architecture on people's behavior, well-being, and the reasons why it is erected, in order to be able to say something more final on the topic. We also need to examine the implications of the normative considerations discussed here in greater depth and examine possible other considerations. In other words, the normative and empirical tasks are unfinished; they have only just begun.

\section{Acknowledgments}

I would like to thank the seminar in political theory at the University of Gothenburg for all the constructive remarks on an earlier draft of this paper. Here I would like to give an extra "shout-out" to Frida Boräng who was a great discussant at this seminar. This work was supported by the Centre for Management of the Built Environment (CMB).

\section{Notes}

1 See http://www.csmonitor.com/The-Culture/Verbal-Energy/2014/0918/Hostilearchitecture-on-the-defensive regarding another form of defensive planning and architecture aimed at countering terrorism and defending against climate change. This topic is beyond the scope of the present paper.

${ }^{2}$ For examples of these designs, see http://www.theguardian.com/society/2014/jun/ 09/boris-johnson-calls-removal-anti-homeless-spikes or http://admin.alternet.org/ activism/activists-pour-concrete-over-spikes-meant-deter-street-sleeping or https://www.fastcodesign.com/3034206/slicker-city/the-hidden-ways-urban-designsegregates-the-poor.The designs align with the Crime Prevention through 
Environmental Design (CPTED) approach. For a review of this approach and its effects, see Cozens and Love (2015). It should also be noted that some of the arguments against using anything like defensive measures at all sometimes comes from the "new urbanism" movement, which is closely affiliated with Jane Jacobs and other giants in the field. However, many of the findings regarding safety and security, which might be of relevance for this paper, have showed that the principles of new urbanism give us mixed results (e.g., Cozens 2007, 2011). For this reason, I am not going to use these principles as such as an argument against defensive architecture. Instead, I am going to discuss the particular instances of defensive designs and what arguments might be for and against these.

${ }^{3}$ There have been discussions in the media, as we can see in endnote ii and in the text below, and some academic discussions on the topic, such as in the book Unpleasant Design (Savicic and Savic 2013; see also Davis 1990; Howell 2001; Mitchell 2003; Petty 2016). However, even though authors take different stances on the issue, they do not discuss it in a systematic fashion by presenting and examining different normative arguments to determine whether they are viable. This is what I aim to do in this paper.

${ }^{4}$ There have been attempts to conduct studies similar to that undertaken in this article (e.g., Mitchell 2003; Fainstein 2012), but these studies do not address - and thus are not relevant to - hostile architecture. It should also be noted that a large part of the ethical discussion of defensive architecture comes from the "continental tradition." This paper is analytic in nature.

${ }^{5}$ There might be a concern here that we somehow lose sight of the political when we discuss individual decisions and decision-makers. But as stated in the introduction, the goal of this paper is to pave the way for making our decisions more transparent and perhaps a bit more well-grounded. To achieve this, the value premise in a political argument needs to be teased, out irrespective of how the decision-making process is construed, which is what I am trying to do to some extent in this paper. Another related worry is that the same normative arguments do not apply to private and public spaces. However, at least the arguments I have found in the debate are actually applicable to both, which makes it easier for us in the current discussion.

${ }^{6}$ I will not discuss what is legal or not and what it implies for what we should do and think about regarding questions of defensive architecture. This is mostly because the law per se does not give us moral reasons to act in a certain way. Only legitimate laws tend to do so. However, since the discussion about "legitimacy" is so complex and will take us far off topic, I will not discuss that here. I will mostly talk about when laws are justified and not what this implies for the individual or specific groups at different points in time,

${ }^{7}$ Even though the use of "hobo" is rather old-fashioned and is viewed as offensive by some, it is often used to denote these sorts of benches, which is why I mention it. An ad for Camden benches is available here: http://www.factoryfurniture.co.uk/ products-camden-bench.php. Other benches require payment to remove spikes from the seating area: http://matadornetwork.com/life/defensive-urban-architecture/.

${ }^{8}$ For an excellent example on the use of spikes and other defensive techniques, see http://www.theguardian.com/cities/2014/jun/12/anti-homeless-spikes-latest-

defen sive-urban-architecture.

9 http://www.theguardian.com/lifeandstyle/gallery/2014/jun/13/anti-skating-boardarchitecture-in-pictures. Skate stoppers are also promoted here: http://www.sinoconcept.com/blog/buy-skate-stoppers-factory/. 
${ }^{10}$ There were about 9.5 million skateboarders in the United States in 1999, and there are many more across the world (Levine 1999, 70). Thus, these measures affect a significant minority population.

${ }^{11}$ Of course, there are many ways in which "well-being" can be understood (e.g., Brülde 1998), and we could also think that some other good is relevant, such as capabilities (Sen 1992; Nussbaum 1992) or resources (Dworkin 1981). However, the different variants of well-being have roughly the same implications with regard to the argument against defensive architecture, and the same is true with regard to the other goods. People in the popular debate also seem more interested in quality of life than in other measures, which together with the other reasons, is why I use the term well-being in the loose sense that I am doing now.

${ }^{12}$ We could, for instance, interpret Flusty (1994) in this way. Utilizing defensive architecture would be worse for all since it will not give people the opportunity to meet; thus, this will lead to tension and greater societal divides. I do not find this argument convincing, but this remains to be seen in the remainder of the paper (see, for example, endnote xi). However, the main reason is that the defensive measures I discuss in this paper are not that effective in keeping people away from public spaces.

${ }_{13}$ There have been studies on the effects of criminalizing the behavior of people without jobs or homes (e.g., Mitchell 2003). However, these are insufficient in drawing conclusions about defensive designs themselves. For example, it is one thing not to be able to make money, such as through begging, and another thing not to be able to beg for money outside of a particular grocery store. The latter might be a hassle because one would have to find a new spot in which to conduct business, but the former might be life threatening because one might not be able to obtain enough money for food.

${ }^{14}$ It has been argued that we cannot measure well-being if it is understood in certain ways (e.g., Brülde 1998), and even if we could, we would not know what the consequences of our actions would be to the extent that we (even in principle) can know beforehand what is the right thing to do (e.g., Gren 2004). However, there are many more positive views on these matters (e.g., Tännsjö 1998), which are quite well-founded; thus, I still believe that it is valuable to discuss what these consequentialist theories might yield.

${ }^{15}$ There are plenty of good reasons as to why we should not give absolute priority to the worst-off (e.g., Daniels and Sabin 2008).

${ }^{16}$ The question of "how many" are affected might be relevant in itself (we should help as many as possible) or instrumentally (it is a proxy for how much well-being is at stake).

${ }^{17}$ A common and, according to many, reasonable normative theory is the "priority view" (e.g., Parfit 1991, 2012).

${ }^{18}$ If we are interested in whether people are provided with opportunities through these defensive measures, we might want to examine, for example, whether people use the new, defensive benches more frequently.

${ }^{19}$ Some people have argued that "respect for persons is simply respect for their rights" (e.g., Thomson 1990, 210-211). However, many disagree with this viewpoint, and we will discuss rights separately below.

${ }^{20}$ One might find this line of reasoning to be a "cynical form of biopolitics," as one of the reviewers stated. I will not take a stand about this issue. Instead, I leave it to the reader to decide what to think about this issue. 
${ }^{21}$ Compare this with what Kant says about respect or with the ideas of direct discrimination (for an excellent overview of the debate on discrimination, see Altman 2015).

${ }^{22} \mathrm{http}: / /$ www.dn.se/sthlm/designen-som-ska-halla-hemlosa-borta/

${ }^{23}$ E.g., Rawls (1971) or McMahan (2013).

${ }^{24}$ There is no guiding principle to determine what to do if most property is not in the rightful hands (e.g., Tännsjö 2008). It is easy to think that everyone should have an equal say about what we should do with these sorts of property, but this is not so. If property is in the wrong hands, it should be restored to the right hands, full stop, in accordance with the absolutist character of libertarian theory.

${ }^{25}$ In today's society, building park benches using money obtained from taxes violates the rights of those who have not consented to the benches. But this fact has nothing to do with whether installing defensive architecture is allowed.

${ }^{26}$ According to the Lockean proviso (Nozick 1974, 202f), one is only free to use a "public good" if, in comparison to the baseline, others are not worse off in an absolute sense because of it. It should be noted that some of the most influential libertarians today have dropped the proviso (Narveson 1999).

${ }^{27}$ Critics of defensive architecture are usually worried about the fact that we have certain laws and a police force that actively push people out of certain areas. However, this is not what defensive architecture does.

${ }^{28} \mathrm{I}$ am appealing to readers' conceded judgments or considered intuitions. This is a common procedure in normative ethics. For a defense of this method, see Rawls (1971) or McMahan (2013).

\section{References}

Allen, J. (2006). Ambient power: Berlin's Potsdamer Platz and the seductive logic of public spaces. Urban Studies, 43(2): 441-455. https://doi.org/10.1080/ 00420980500416982

Altman, A (2015). "Discrimination", In Zalta, Edward N. (Ed.), The Stanford Encyclopedia of Philosophy. Retrieved from: http://plato.stanford.edu/ archives/fall2015/entries/discrimination/

Andersson, K. (2014). Fientlig arkitektur exkluderar [Hostile architecture excludes]. Tidskriften Stad 6: 58.

Anderson, E. S. (1999). What Is the Point of Equality? Ethics, 109(2): 287-337. https://doi.org/10.1086/233897

Andreou, A. (2015). Anti-homeless spikes: Sleeping rough opened my eyes to the city's barbed cruelty. The Guardian, 19. Retrieved June 01, 2016, from https://www.theguardian.com/society/2015/feb/18/defen sive-architecturekeeps-poverty-undeen-and-makes-us-more-hostile

Aneljung, S., \& Ederyd, J. (2015). Den offentliga platsens exkluderande och inkluderande förmåga [The excluding and including abilities of public space]. Bachelor essay. Retrieved from: http://stud.epsilon.slu.se/8047/

Arneson, R.J. (1989). Equality and Equal Opportunity for Welfare. Philosophical Studies 56: 77-93. https://doi.org/10.1007/BF00646210

Blakely, E.J., and M.G. Snyder (eds.). (1997). Fortress America: Gated Communities in the United States. Washington D.C.: Brookings Institution Press.

Brülde, B. (1998). Human Good. Gothenburg: Acta Universitatis Gothoburgenes. 
Cozens, P., \& Love, T. (2015). A review and current status of crime prevention through environmental design (CPTED). Journal of Planning Literature 30: 4: 393-412. https://doi.org/10.1177/0885412215595440

Davis, M. (1992). City of Quartz: Excavating the Future in Los Angeles. New York: Vintage.

Daniels, N., \& Sabin, J. E. (2008). Setting limits fairly: learning to share resources for health. Oxford University Press.

Darwall, S. L. (2006). The second-person standpoint: Morality, respect, and accountability. Harvard University Press.

De Grandis, G. (2013). A Starting Point for a Practical and Methodological Discussion. The Journal of Urbanism 1: 34-47.

Donnelly M.K. (2008). Alternative and mainstream: revisiting the sociological analysis of skateboarding. In M. Atkinson, K. Young (Eds), Tribal Play: Subcultural Journeys Through Sport (pp.197-214). JAI Press, Bingley, W. Yorkshire. https://doi.org/10.1016/S1476-2854(07)00208-7

Dworkin, R. (1981). What is Equality? Part 2: Equality of Resources. Philosophy and Public Affairs 10: 283-345.

Edin, F. (2014). The Message is the Medium: Bum-proof Benches from an Ideological Perspective. (Master's thesis, University of Lund (in Swedish)). Retrieved from: https://lup.lub.lu.se/student-papers/search/publication/4618913

Fainstein, S. S. (2010). The Just City. New York: Cornell University.

Flusty, S. (1994). Building Paranoia: The Proliferation of Interdictory Space and the Erosion of the Spatial Justice. Ram Distribution.

Ellickson, R. (1996). Controlling Chronic Misconduct in City Spaces: Of Panhandlers, Skid Rows and Public-Space Zoning. Yale Law Journal 105(5): 1165-1248. https://doi.org/10.2307/797175

Forsman, L., Eriksson, A. (2001). Skateboarding Injuries of Today. Journal of Sports Medicine 35: 325-328. https://doi.org/10.1136/bjsm.35.5.325

Gren, J. (2004). Applying utilitarianism: The problem of practical action-guidance. Acta Universitatis Gothoburgenes. Retrieved from: https:/gupea.ub.gu.se/ bitstream/2077/4565/1/gupea_2077_4565_1.pdf

Harvey, D. (2008). The right to the city. The City Reader 6: 23-40.

Howell, O. (2001). The Poetics of Security: Skateboarding, Urban Design, and the New Public Space. Retrieved from: http://www.urbanstructure.com/ urbanaction/PS.html.

Kamm, F. (2007). Intricate Ethics: Rights, Responsibilities, and Permissible Harms. Oxford: Oxford University Press. https://doi.org/10.1093/acprof:oso/ 9780195189698.001.0001

Kant, I. 1785 (2008). The Groundwork of the Metaphysics of Morals. Cambridge: VA: Wilder.

Karsten, L. and E. Pel. (2000). Skateboarders Exploring Urban Public Space: Ollies, Obstacles and Conflicts. Journal of Housing and the Built Environment 15(4): 327-340. https://doi.org/10.1023/A:1010166007804

Kelling, G., and C. Coles. (1996). Fixing Broken Windows: Restoring Order and Reducing Crime in our Communities. New York: Free Press.

Lee, A.C.K. and R. Maheswaran. (2011). The Health Benefits of Urban Green Spaces: A Review of the Evidence. Journal of Public Health 33(2): 212-222. https://doi.org/10.1093/pubmed/fdq068 
Lefebvre, H. (1968). The right to the city. In Kofman, E. and Lebas, E. (Eds.), Writings on cities (pp. 63-185). Oxford: Blackwell.

Levine, M. (1999, July 26). The Birdman. The New Yorker, 68.

Lockton, D. (2011). Architecture, urbanism, design and behaviour: a brief review. Retrieved June 01, 2016, from https://www.researchgate.net/profile/ Dan_Lockton/publication/260752108_Architecture_urbanism_design_and_be haviour_a_brief_review/links/00b7d532230442bb8c000000.pdf

Loukaitou-Sideris, A. (1999). Hot Spots of Bus Stop Crime: The Importance of Environmental Attributes. Journal of the American Planning Association 65(4): 395-411.Lindberg, A. (2015, April 6). Tiggarna är ingen ohyra [Beggars are not vermin]. Aftonbladet. Retrieved June 01, 2016, from http://www.aftonbladet.se/ledare/ledarkronika/anderslindberg/article20585083 . $\mathrm{ab}$

Lustenberger, T.; Talving, P.; Barmparas, G.; Schnüriger, B.; Lam, L.; Inaba, K.; Demetriades, D. (2010). Skateboard-related Injuries: Not to be Taken Lightly. A National Trauma Databank Analysis. Journal of Trauma-Injury Infection and Critical Care 69(4): 924-927. https://doi.org/10.1097/ TA.0b013e3181b9a05a

McMahan, J. (2005). Causing Disabled People to Exist and Causing People to Be Disabled. Ethics, 116(1), 77-99. https://doi.org/10.1086/454367

McMahan, J. (2011). Moral intuition. In LaFolette, H. and Persson, I. (Eds.), The Blackwell Guide to Ethical Theory, 2nd Ed. Blackwell Publishing.

Mitchell, D. (2003). The Right to the City: Social Justice and the Fight for Public Space. New York: Guilford Publications.

Mitchell, R., Popham, F. (2008). "Effect of Exposure to Natural Environment on Health Inequalities: An Observational Population Study." The Lancet 372(9650): 1655-1660. https://doi.org/10.1016/S0140-6736(08)61689-X

Narveson, J. (1988). The Libertarian Idea. Philadelphia: Temple University Press.

Narveson, J. (2011). Libertarianism. In LaFolette, H. and Persson, I. (Eds.), The Blackwell Guide to Ethical Theory, 2nd Ed. Blackwell Publishing.

Narveson, J. (1999). Property rights: Original acquisition and Lockean provisos. Public Affairs Quarterly, 13: 205-227.

Nozick, R. (1974). Anarchy, State and Utopia. New York: Basic Books.

Nussbaum, A. (1992). Human Functioning and Social Justice: In Defense of Aristotelian Essentialism. Political Theory 20(2): 202-246. https://doi.org/ $10.1177 / 0090591792020002002$

Parfit, D. (1991). Equality or Priority? The Lindley Lecture: University of Kansas Press.

Parfit, D. (2012). Another defence of the priority view. Utilitas, 24(03): 399-440. https://doi.org/10.1017/S095382081200009X

Petty, J. (2016). The London Spikes Controversy: Homelessness, Urban Securitisation and the Question of 'Hostile Architecture'. International Journal for Crime, Justice and Social Democracy 5: 67-81. https://doi.org/10.5204/ ijcjsd.v5i1.286

Randrup. (2010). Health Promoting Outdoor Environments: Associations between Green Space, and Health, Health-related Quality of Life and Stress Based on a Danish National Representative Survey. Scandinavian Journal of Public Health, 38(4): 411-417

Rawls, J. (1971). A Theory of Justice. Cambridge, MA: Harvard University Press. 
Savicic, G. and Savic, S. (2013). Unpleasant Design. Belgrade: G.L.O.R.I.A.

Sen, A. (1992). Inequality Reexamined. Oxford: Oxford University Press.

Shantz, B.M., Kearns, R. and Collins, D. (2008). Intolerance for Noise and Disorder: Questioning 'Publicness' of Auckland's Lower Queen Street. Urban Policy and Research 26(1): 39-55. https://doi.org/10.1080/08111140701583745

Sidgwick, H. (1907). The Methods of Ethics. London: Macmillan.

Swanton, C. (2004). Virtue Ethics: A Pluralistic View. Oxford: Oxford University Press

Temkin, L.S. (1993). Inequality. Oxford: Oxford University Press.

Temkin, L.S. (2003). Equality, Priority or What? Economics and Philosophy 1: 6187. https://doi.org/10.1017/S0266267103001020

Thaler R. H., Sunstein C. R. (2008). Nudge: Improving Health, Wealth, and Happiness. London and New Haven: Yale University Press.

Thörn, C. (2011). Soft policies of exclusion: entrepreneurial strategies of ambience and control of public space in Gothenburg, Sweden. Urban Geography, 32(7): 989-1008. https://doi.org/10.2747/0272-3638.32.7.989

Tännsjö, T. (1998). Hedonistic Utilitarianism. Edinburgh: Edinburgh University Press.

Titheridge, H., Christie, N., Mackett, R., Oviedo Hernández, D., Ye, R. (2014). Transport and Poverty A review of the evidence. Retrieved from: https://www.ucl.ac.uk/transport-institute/pdfs/transport-poverty

Wood, A. W. (1999). Kant's Ethical Thought. Cambridge: Cambridge University Press. https://doi.org/10.1017/CBO9781139173254

Woolley, H. and R. Johns. (2001). Skateboarding: The City as a Playground. Journal of Urban Design 6(2): 211-230. https://doi.org/10.1080/13574800120057845 